\title{
The phosphodiesterase type 2 inhibitor BAY 60-7550 reverses functional impairments induced by brain ischemia by decreasing hippocampal neurodegeneration and enhancing hippocampal neuronal plasticity
}

Citation for published version (APA):

Soares, L. M., Meyer, E., Milani, H., Steinbusch, H. W. M., Prickaerts, J., \& de Oliveira, R. M. W. (2017). The phosphodiesterase type 2 inhibitor BAY 60-7550 reverses functional impairments induced by brain ischemia by decreasing hippocampal neurodegeneration and enhancing hippocampal neuronal plasticity. European Journal of Neuroscience, 45(4), 510-520. https://doi.org/10.1111/ejn.13461

Document status and date:

Published: 01/02/2017

DOI:

10.1111/ejn.13461

Document Version:

Publisher's PDF, also known as Version of record

\section{Document license:}

Taverne

Please check the document version of this publication:

- A submitted manuscript is the version of the article upon submission and before peer-review. There can be important differences between the submitted version and the official published version of record. People interested in the research are advised to contact the author for the final version of the publication, or visit the $\mathrm{DOI}$ to the publisher's website.

- The final author version and the galley proof are versions of the publication after peer review.

- The final published version features the final layout of the paper including the volume, issue and page numbers.

Link to publication

\footnotetext{
General rights rights.

- You may freely distribute the URL identifying the publication in the public portal. please follow below link for the End User Agreement:

www.umlib.nl/taverne-license

Take down policy

If you believe that this document breaches copyright please contact us at:

repository@maastrichtuniversity.nl

providing details and we will investigate your claim.
}

Copyright and moral rights for the publications made accessible in the public portal are retained by the authors and/or other copyright owners and it is a condition of accessing publications that users recognise and abide by the legal requirements associated with these

- Users may download and print one copy of any publication from the public portal for the purpose of private study or research.

- You may not further distribute the material or use it for any profit-making activity or commercial gain

If the publication is distributed under the terms of Article $25 \mathrm{fa}$ of the Dutch Copyright Act, indicated by the "Taverne" license above,

Download date: 26 Apr. 2023 


\title{
The phosphodiesterase type 2 inhibitor BAY 60-7550 reverses functional impairments induced by brain ischemia by decreasing hippocampal neurodegeneration and enhancing hippocampal neuronal plasticity
}

\author{
Ligia Mendes Soares, ${ }^{1}$ Erika Meyer, ${ }^{1}$ Humberto Milani, ${ }^{1}$ Harry W. M. Steinbusch, ${ }^{2}$ Jos Prickaerts ${ }^{2}$ and \\ Rúbia M. Weffort de Oliveira ${ }^{1}$ \\ ${ }^{1}$ Department of Pharmacology and Therapeutics, State University of Maringá, Av. Colombo, 5790, CEP 87020-900, Maringá, \\ Paraná, Brazil \\ ${ }^{2}$ Department of Psychiatry and Neuropsychology, School for Mental Health and Neuroscience, Maastricht University, Maastricht, \\ The Netherlands
}

Keywords: antidepressant, anxiolytic, cognition, global brain ischemia, phosphodiesterase 2 inhibitor

Edited by Paul Bolam

Received 16 August 2016, revised 26 October 2016, accepted 31 October 2016

\begin{abstract}
Cognitive and affective impairments are the most characterized consequences following cerebral ischemia. BAY 60-7550, a selective phosphodiesterase type 2 inhibitor (PDE2-I), presents memory-enhancing and anxiolytic-like properties. The behavioral effects of BAY 60-7550 have been associated with its ability to prevent hydrolysis of both cyclic adenosine monophosphate (cAMP) and cyclic guanosine monophosphate (cGMP) thereby interfering with neuronal plasticity. Here, we hypothesize that PDE2-I treatment could promote functional recovery after brain ischemia. Mice C57BI/6 were submitted to bilateral common carotid artery occlusion (BCCAO), an experimental model of transient brain ischemia, for 20 min. During 21 days after reperfusion, the animals were tested in a battery of behavioral tests including the elevated zero maze (EZM), object location task (OLT) and forced swim test (FST). The effects of BAY 60-7550 were evaluated on neuronal nuclei (NeuN), caspase-9, cAMP response element-binding protein (CREB), phosphorylated CREB (pCREB) and brain-derived neurotrophic factor (BDNF) expression in the hippocampus. BCCAO increased anxiety levels, impaired hippocampus-dependent cognitive function and induced despair-like behavior in mice. Hippocampal neurodegeneration was evidenced by a decrease in NeuN and increase incaspase-9 protein levels in BCCAO mice. Ischemic mice also showed low BDNF protein levels in the hippocampus. Repeated treatment with BAY 60-7550 attenuated the behavioral impairments induced by BCCAO in mice. Concomitantly, BAY 60-7550 enhanced expression of pCREB and BDNF protein levels in the hippocampus of ischemic mice. The present findings suggest that chronic inhibition of PDE2 provides functional recovery in BCCAO mice possibly by augmenting hippocampal neuronal plasticity.
\end{abstract}

\section{Introduction}

Phosphodiesterases (PDEs) are metallophosphohydrolase enzymes that ubiquitously metabolize the second messengers cyclic adenosine monophosphate (cAMP) and cyclic guanosine monophosphate (cGMP) to their respective inactive $5^{\prime}$-monophosphates (Conti \& Beavo, 2007). Phosphodiesterases are subdivided into 11 structurally related but functionally distinct families (PDE1 to PDE11) classified according to different posttranslational modifications and the cyclic nucleotide substrate (cAMP and/or cGMP) that they hydrolyze (Maurice et al., 2014). Some PDEs specifically hydrolyze cAMP (PDE4, PDE7, and PDE8), whereas others hydrolyze cGMP (PDE5,

Correspondence: Rúbia M. Weffort de Oliveira, as above.

E-mail: rmmwoliveira@uem.br
PDE6, and PDE9). Still others hydrolyze both cyclic nucleotides (PDE1, PDE2, PDE3, PDE10, and PDE11; Conti \& Beavo, 2007).

In general, phosphodiesterases are involved in numerous physiological processes such as cell proliferation and differentiation, gene expression, inflammation, apoptosis, and metabolism (Maurice et al., 2014). Growing attention has been given to the potential of PDEs as therapeutic targets for affective disorders and/or diseases affecting cognitive functions (Wang et al., 2015). The utility of blocking cyclic nucleotide hydrolysis by selective PDE inhibitors (PDE-I) has been recognized in several brain conditions, including depression (Berton \& Nestler, 2006; Li et al., 2009), schizophrenia (Soares et al., 2015; Heckman et al., 2016; Shim et al., 2016), Alzheimer's disease (Sallustio \& Studer, 2016; Su et al., 2016; Zhuo et al., 2016) and ischemia (Hu et al., 2016; Kim et al., 2016; Moretti 
et al., 2016; Soares et al., 2016; Takagi \& Hara, 2016). Moreover, PDE-Is have been considered therapeutic tools for the treatment of cognitive decline (Heckman et al., 2016) and affective disorders (Zhu et al., 2001) often impaired in these brain conditions.

Phosphodiesterase 2 (PDE2) hydrolyzes both cAMP and cGMP, although cGMP is the preferred substrate and effector (Trabanco et al., 2016). PDE2 is expressed in the peripherical and central nervous system (CNS) in diverse number of tissues and cell types. In the brain, PDE2 is widely expressed in the hippocampus, cerebral cortex and striatum, areas related to cognitive and emotional functions (Conti \& Beavo, 2007). The pattern of PDE2 brain expression makes it critical in controlling several physiological functions and pathological conditions (Zhang et al., 2015). In the context of cognition, activation of cAMP/protein kinase A (PKA)/cAMP responsive element-binding protein (CREB) and cGMP/protein kinase $\mathrm{G}$ (PKG)/CREB signaling pathways has been associated with longterm potentiation and memory formation (Kanterewicz et al., 2000; Matsumoto et al., 2006; Reneerkens et al., 2009; Bollen et al., 2014).

The PDE2 inhibitor (PDE2-I) BAY 60-7550 (2-[3,4-dimethoxybenzyl]-7-\{(1R)-1-[(1R)-1-hydroxyethyl]-4-phenylbutyl $\}-5-$ methylimidazo[5,1-f] $[1,2,4]$ triazin-4[3H]-one) exerted anxiolytic- and antidepressant-like effects in mice (Masood et al., 2008, 2009; Ding et al., 2014). BAY 60-7550 reversed cognitive impairments and increased the expression of such transcription factors as Elk-1, CREB, transducer of regulated CREB activity 1 (TORC1), and the protein levels of brain-derived neurotrophic factor (BDNF) in stressed mice (Xu et al., 2015). BAY 60-7550 also improved memory acquisition and consolidation in young and aged rodents in both the object recognition and social recognition tasks (Boess et al., 2004; Domek-Lopacinska \& Strosznajder, 2008; Rodefer et al., 2012). Moreover, BAY-60-7550 prevented memory deficits that were induced by scopolamine and MK-801 in rats (Reneerkens et al., 2013) and improved memory in the APPswe/PS1dE9 mouse model of Alzheimer's disease (Sierksma et al., 2013).

Based on its pharmacological properties, BAY 60-7550 is likely to be a promising PDE2-I to treat the functional impairments induced by brain ischemia, a condition in which survivors can develop cognitive impairments, depression and anxiety (Moulaert et al., 2010; Geri et al., 2014). Here, we investigated whether BAY 60-7550 treatment rescues cognitive and affective impairments induced by transient brain ischemia in C57B1/6 mice. We also investigated the effects of BAY 60-7550 on the hippocampal expression of mature neuronal nuclei marker (NeuN), caspase-9, CREB, phosphorylated CREB (pCREB), and BDNF after brain ischemia.

\section{Material and methods}

\section{Animals}

Three-months-old male C57bL/6 mice (25-30 g) were obtained from the central vivarium of the State University of Maringá, Paraná, Brazil. The animals were allowed to acclimate to controlled temperature $\left(22 \pm 1{ }^{\circ} \mathrm{C}\right)$ with a $12 \mathrm{~h} / 12 \mathrm{~h}$ light/dark cycle (lights on at 7:00 AM) for 4 weeks prior to the experiments. The animals were housed in groups $(n=3-5)$ and were given standard commercial chow and tap water ad libitum. All animal experiments were approved by the ethical committee by the local Ethics Committee on Animal Experimentation of the State University of Maringá (CEEA 073/2013) and are conformed to the U.S. National Institutes of Health and Brazilian College for Animal Experimentation guidelines. All efforts were made to minimize the number of animals used and their suffering.

\section{Surgery}

Transient brain ischemia was induced by bilateral common carotid artery occlusion (BCCAO) as previously described (Soares et al., 2016). The mice were anesthetized with a mixture of isoflurane (Isoforine ${ }^{\circledR}$, Cristália, São Paulo, Brazil) and oxygen delivered through a universal vaporizer (Oxigel, São Paulo, Brazil). The mixture delivered to the animal was monitored to supply a minimal isoflurane concentration for sufficient anesthesia and was maintained with 1.3$1.5 \%$ isoflurane in $100 \%$ oxygen for about 6 min during which an incision was made in the ventral neck to expose the common carotid arteries. Next the arteries were occluded using aneurysm clips (ADCA, Barbacena, Brazil) during 20 min. Rectal temperature was carefully monitored during surgery and occlusions and maintained at $37.5^{\circ} \mathrm{C}$. At the end of each occlusion, the aneurism clips were removed, and the carotid arteries were visually inspected for reperfusion. Then, each animal was again anesthetized for $2 \mathrm{~min}$ and the incision was closed with sutures. Sham-operated animals were subjected to the same anesthetic and surgical interventions, with the exception that the carotid arteries remained intact.

\section{Drug administration}

Vehicle $(0.5 \%$ methylcellulose and $2 \%$ Tween80) or BAY $60-7550$ (a gift from Dr Prickaerts, Maastricht University, The Netherlands) were administered by oral gavage (p.o.) in a volume of $10 \mathrm{~mL} / \mathrm{kg}$. Animals received vehicle or BAY 60-7550 immediately after the reperfusion and then daily between 4:00 PM to 5:00 PM during 21 days. The dose of $1.0 \mathrm{mg} / \mathrm{kg}$ BAY 60-7550 was based on previous experiments showing its pro-cognitive and anxiolytic-like effects (Boess et al., 2004; Masood et al., 2009; Reneerkens et al., 2013). Three experimental groups were randomly generated: Sham + vehicle (sham + veh, $n=12), \quad \mathrm{BCCAO}+$ vehicle $(\mathrm{BCCAO}+\mathrm{veh}$, $n=11), \mathrm{BCCAO}+\mathrm{BAY} 60-7550(\mathrm{BCCAO}+\mathrm{BAY}, n=11)$.

\section{Experimental design}

Behavioral tests started 7 days after the surgery and were conducted from 8:00 AM to 11:00 AM. As seen in Fig. 1, over 14 days after the surgeries, the animals were consecutively evaluated in the elevated zero maze (EZM; day 7), open field test (OFT; day 9), object location test (OLT; days 13, 14, 16, and 18), and forced swim test (FST, day 21). The animal behaviors were video recorded and analyzed with the help of the ANYMAZE ${ }^{\circledR}$ software (Stoelting, Wood Dale, USA). At the end of behavioral testing the animals were killed and had their brains processed for immunohistochemical or western blotting analysis.

\section{Behavioral testing}

\section{Elevated zero maze}

The elevated zero maze (EZM) was used to measure anxiety-like behavior (Shepherd et al., 1994). The apparatus consisted of a circular runway (diameter $46 \mathrm{~cm}$, width $5.5 \mathrm{~cm}$ ) made from gray plastic material and elevated $20 \mathrm{~cm}$ above the floor. The arena was divided into four arms: two opposing open arms with a low border (height $3 \mathrm{~mm}$ ) to prevent the mouse from stepping down, and two opposing closed arms with sidewalls (height $11 \mathrm{~cm}$ ). Each mouse was placed 


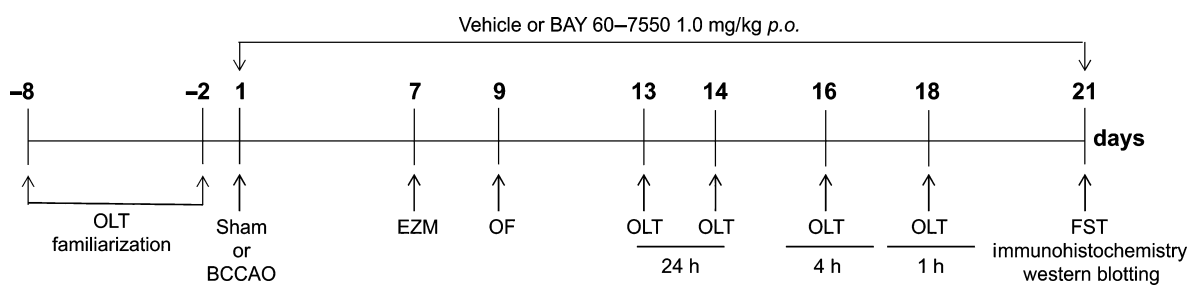

FIG. 1. Experimental design. Vehicle or BAY $60-75501.0 \mathrm{mg} / \mathrm{kg}$ were p.o. administered daily during 21 days. The treatment started at day $1,1 \mathrm{~h}$ after sham or BCCAO surgeries. From days 7 to 21 after reperfusion, mice were subjected to behavioral testing. After the last behavioral test, mice were killed and their brains were processed for immunohistochemical and western blotting analysis. EZM, elevated zero maze; OF, open field; OLT, object location test; FST, forced swim test.

individually into one of the open arms and was allowed to explore the arena for $6 \mathrm{~min}$. After each session the maze was thoroughly cleaned using $70 \%$ ethanol and dried. The time spent in the open arms of the maze was recorded and corrected for freezing behavior by subtracting the time (in seconds) it takes to enter into a closed arm for the first time from the total time spent in the maze.

\section{Open field test}

The OF was made of a wooden square box $(70 \times 70 \mathrm{~cm})$ with a $40 \mathrm{~cm}$ high wall. The mice were individually placed in the center of the $\mathrm{OF}$, and allowed to explore it during $10 \mathrm{~min}$. After each session, the OF was cleaned using $70 \%$ ethanol and water and then dried. The total distance traveled (in meters) was recorded.

\section{Object location test}

Spatial memory was evaluated in the object location test (OLT) as described before (Vanmierlo et al., 2016). The apparatus consisted of a circular arena $(43 \mathrm{~cm}$ diameter, $40 \mathrm{~cm}$ high wall) made of transparent polyvinylchloride. Three different sets of objects, available in triplicate, were used: (i) a little glass bottle $200 \mathrm{~mL}$ (maximal diameter 5.5 and $15.0 \mathrm{~cm}$ height) filled with water, (ii) a massive porcelain cube $(9.5 \times 6.5 \times 6.5 \mathrm{~cm})$, and (iii) a massive aluminum cube with a tapering top $(4.5 \times 4.5 \times 8.5 \mathrm{~cm})$. One week before BCCAO, the animals were familiarized with the OLT, i.e., they were initially allowed to explore the circular arena (without any objects) in 2 days consecutively ( $3 \mathrm{~min} /$ day). On the following 4 days, the mice were adapted to the test until they showed a stable discrimination performance, i.e., good object discrimination at a $1 \mathrm{~h}$ interval (Akkerman et al., 2012). Subsequently, BCCAO was induced and the actual OLT testing took place at 13, 14, 16, and 18 days after BCCAO. A testing session consisted of two trials, with each trial lasting $4 \mathrm{~min}$. Before each trial, mice were placed in an empty cage for $4 \mathrm{~min}$, to prime their attention. During the first trial (T1) the arena contained two identical objects at fixed locations. A mouse was introduced into the arena by placing it with its nose to the middle of the wall. After the first exploration period the mouse was placed back in its home cage. After a predetermined time interval of 1,4 , or $24 \mathrm{~h}$, the mouse was put back into the arena for the second trial (T2). However, one of the objects had shifted location, which was randomized in a balanced manner over the groups and the different sessions to reduce potential bias due to preference for particular objects or location. The time spent exploring the two objects during T1 and T2 was recorded manually by an experienced observer. The discrimination index (D2) indicates whether the mouse spends more time exploring the relocated object, while correcting for the total exploration time in T2.
D2 = (exploration time novel location - exploration time familiar location)/(exploration time novel location + exploration time familiar location). Thus, even if a treatment would affect exploratory behavior, the D2 index will be comparable between conditions (Akkerman et al., 2012). Exploratory behavior was defined as follows: directing its nose to the object at a distance of no more than $1 \mathrm{~cm}$ and/or touching the object with its nose. Sitting on the object was not considered exploration. Animals which explore the objects less than $5 \mathrm{~s}$ were excluded from analysis as sufficient exploratory behavior is required to have a reliable memory performance (Akkerman et al., 2012). All objects and the arena were cleaned thoroughly with $70 \%$ ethanol between sessions.

\section{Forced swim test}

Animals were tested in the forced swim test (FST), a well-known test for screening of antidepressants in rodents (Porsolt et al., 1978). Each mouse was individually placed in a glass cylinder (diameter $10 \mathrm{~cm}$, height $25 \mathrm{~cm}$ ) filled with water at $25^{\circ} \mathrm{C}$ during $6 \mathrm{~min}$. Immobility was defined as follows: making no movements or only making those movements necessary to keep the nose above the water. The immobility time during the last $4 \mathrm{~min}$ of the swimming session and latency to first immobility was registered.

\section{Immunohistochemistry}

Half of the mice were deeply anesthetized with sodium thiopental i.p. (Thiopentax ${ }^{\circledR}$, Cristália, São Paulo, Brazil) and transcardially perfused with $0.1 \mathrm{~m}$ phosphate-buffered saline (PBS) followed by $4 \%$ paraformaldehyde in $0.2 \mathrm{M}$ phosphate buffer (PB). The brains were removed, post fixed in the same fixative for $24 \mathrm{~h}$ and cryoprotected by immersion in $30 \%$ sucrose for $48 \mathrm{~h}$. Then, the brains were quickly frozen and kept at $-80{ }^{\circ} \mathrm{C}$ until analysis were carried out. Frozen tissue was serially sectioned on a cryostat (Criocut 1800, Reichert-Jung, Heidelberg, Germany) into $30 \mu \mathrm{m}$ coronal sections at -1.22 to $-2.70 \mathrm{~mm}$ posterior to bregma (Franklin \& Paxinos, 1997) and collected into six alternative Eppendorf tubes containing PBS $0.1 \mathrm{M}$ plus sodium azide $0.1 \%$ and stored at $4{ }^{\circ} \mathrm{C}$.

Free-floating sections were quenched in $1 \% \mathrm{H}_{2} \mathrm{O}_{2}$ for $30 \mathrm{~min}$ and then blocked with $2 \%$ bovine serum albumin (BSA) in $0.1 \mathrm{~m}$ PBS for $60 \mathrm{~min}$ at room temperature. The sections were incubated overnight with the polyclonal antibody rabbit anti-pCREB (1: 150; Cell Signaling, Danvers, MA, USA) in PBS $0.1 \mathrm{~m}$ containing $0.3 \%$ Triton $\mathrm{X}-100$ at room temperature. After, the sections were incubated with the respective biotinylated secondary antibody (1:500; Santa Cruz Biotechnology, Santa Cruz, CA, USA) for $2 \mathrm{~h}$ and incubated in $\mathrm{ABC}$ solution (Vectastain Elite $\mathrm{ABC}$ Kit, Vector Laboratories, Burlingame, CA, USA) for $2 \mathrm{~h}$ at room temperature. The peroxidase 
reaction was performed using 3-3'-diaminobenzidine (DAB; Sigma) and $0.05 \% \mathrm{H}_{2} \mathrm{O}_{2} . \mathrm{NiCl}_{2}$ was added to the DAB solution to increase the staining contrast. The sections were mounted on gelatin-coated slides and coverslipped with Permount ${ }^{\circledR}$. With the aim of IMAGEJ, prefixed digital microscopic areas were captured bilaterally for the CA1 $\left(0.11 \mathrm{~mm}^{2}\right)$, CA3 $\left(0.15 \mathrm{~mm}^{2}\right)$, and DG $\left(0.9 \mathrm{nmm}^{2}\right)$. Photomicrograph was taken at every selected area with a digital camera (QColor3, Ontario, Canada) attached to an Olympus AX-70 microscope $(20 \times$ objective; Olympus BX41 microscope, Tokyo, Japan). Quantitative evaluation of pCREB immunoreactivity (IR) was performed by taking the integrated optical density (IOD) measurements. With the aim of IMAGEJ software (NIH, Bethesda, MD, USA), the images were converted to 32-bit image and the background subtracted. The threshold for positive signal was predefined, and the IOD obtained. Values were presented as the mean \pm SEM of the sections per animal of both brain hemispheres.

\section{Western blotting}

Half of the mice were decapitated, their brains carefully removed and the whole hippocampus isolated by microdissection and snapfrozen in liquid nitrogen. The tissue samples were lysed with lysis buffer ( $50 \mathrm{~mm}$ Tris, $600 \mathrm{~mm} \mathrm{NaCl}, 1 \mathrm{~mm}$ EDTA) containing protease inhibitor (Sigma-Aldrich, St. Louis, MO, USA) and centrifuged at $16700 \mathrm{~g}$ for 20 minutes at $4{ }^{\circ} \mathrm{C}$. The supernatant was assayed for total protein concentrations using the Bio-Rad Lowry Protein Assay (Bio-Rad Laboratories Inc., Hercules, USA).

Protein levels were assessed of NeuN, caspase-9, CREB, and BDNF. Hippocampal homogenates (30 $\mu \mathrm{g}$ protein each) in sample buffer were separated on a $15 \%(\mathrm{BDNF})$ or $12 \%(\mathrm{NeuN}$, caspase 9 , CREB) SDS-PAGE gel, using a total of four different blots to measure all different proteins. After protein transfer onto a nitrocellulose membrane (Bio-Rad Laboratories, Hercules, USA), membranes were blocked (2\% BSA in TBS buffer) and incubated with the primary antibody at $4{ }^{\circ} \mathrm{C}$ overnight at the following dilutions: rabbit antiNeuN (1 : 500; Abcam, Cambridge, MA, USA) mouse anti-Caspase 9 (1 : 100; Santa Cruz Biotechnology, Santa Cruz, CA, USA), rabbit anti-CREB (1 : 500; Cell Signaling), rabbit anti-BDNF (1: 400; Santa Cruz Biotechnology), and rabbit anti- $\beta$-actin (1:5000; Abcam). After a washing step with TBS, membranes were incubated for $2 \mathrm{~h}$ with horse radish peroxidase-conjugated donkey anti-rabbit $\operatorname{IgG}(1: 5000 ;$ Abcam) or donkey anti-mouse $\operatorname{IgG}(1: 5000$; Abcam) and were finally developed using ECLplus ${ }^{\circledR}$ (Invitrogen, Carlsbad, CA, USA). In order to assess the protein control ( $\beta$-actin) all blots were stripped with harsh stripping buffer (20\% SDS $10 \%$, $12.5 \%$ Tris $\mathrm{HCl} 0.5 \mathrm{M}$ and $0.8 \% \beta$-mercaptoethanol in $\mathrm{H}_{2} \mathrm{O}$ ). Bands were visualized using ChemiDoc Imaging Systems (Bio-Rad, Hercules, CA, USA). Intensities of specific bands were quantified using IMAGEJ (NIH, Bethesda, MD, USA) and normalized to $\beta$-actin protein levels.

\section{Statistical analysis}

SAS 9.3 software (Cary, NC, USA) was used for the statistical analysis. All data were presented as mean \pm SEM of experimental groups and examined for assumptions of normal distribution (D'Agostino and Pearson omnibus test) and homoscedasticity (Levene's test). A proportion-like $t$-test was used to quantify the effects of BCCAO on mortality rate. As behavioral data followed normal distribution and homoscedasticity, one-way ANOVA was used for between-group comparisons. If a main effect of Group was found, then Tukey-Kramer's multiple range test was used to distinguish between them. Functional spatial memory within the groups, i.e. a D2 value in the OLT that differs significantly from 0 , was analyzed with a one-sample $t$-test. The immunohistochemistry and western blotting data were analyzed using a generalized linear model with a Gamma distribution. Values of $P<0.05$ were considered statistically significant.

\section{Results}

\section{Mortality rate}

Overall, 50 animals entered the experiment. No death was found in the sham + veh group $(0 \%, 0 / 12)$. However, a significant effect of BCCAO was detected, as seen by 10 deaths in 21 animals $(10 / 21$, $52.4 \%, P=0.01)$. BAY $60-7550$ reduced the mortality in mice subjected to BCCAO $(35.3 \%, 6 / 17)$, although no statistical significant difference was detected among the groups $(P=0.1)$.

\section{BAY 60-7550 ameliorates cognitive and emotional impairments in BCCAO mice}

An ANOva revealed difference in the time spent in the open arms of the EZM $\left(F_{2,33}=4.41, \quad P=0.02\right)$. As shown in Fig. 2A, $\mathrm{BCCAO}+$ veh group spent less time in the open arms of EZM when compared to sham + veh group $(P=0.1)$. Otherwise, BAY 60-7550 increased the time spent in the open arms of BCCAO mice as compared to controls $(P=0.01)$, indicating an anxiolytic-like effect. No differences on total distance traveled in the OF test was observed among the experimental groups $\left(F_{2,33}=1.44, P=0.25\right.$, Fig. $\left.2 \mathrm{~B}\right)$.

In the OLT (Fig. 2C, D and E), ANOva indicated a significant effect at a $1 \mathrm{~h}\left(F_{2,32}=34.66, P<0.0001\right)$ and $4 \mathrm{~h}\left(F_{2,32}=11.17\right.$, $P=0.0002)$ but not at $24 \mathrm{~h}\left(F_{2,32}=0.61, P=0.54\right)$ intervals. A significant effect of brain ischemia was observed as BCCAO + veh group had lower D2 scores than sham + veh group (at $1 \mathrm{~h}$, $P=0.0001$ and at $4 \mathrm{~h}, P=0.0003$ ), indicating that the ability for distinguishing object location, i.e., memory location, was negatively impacted by ischemia, in comparison to sham. In contrast, BCCAO animals that received BAY 60-7550 were preserved from that memory impairment, as the D2 scores were increased when compared to $\mathrm{BCCAO}+$ veh group $(1 \mathrm{~h}, P=0.0001 ; 4 \mathrm{~h}, P=0.004$ When examining the D2 scores for 1 and $4 \mathrm{~h}$ intervals in more detail, sham + veh and BCCAO + BAY groups showed D2 scores different from zero, further indicating that they could distinguish between the familiar and the novel location $(1 \mathrm{~h}, t=4.13-6.22, P=0.002$ 0.0001 and $4 \mathrm{~h}, t=3.09-3.13, P=0.01)$ while BCCAAO + veh group could not $(P>0.05)$.

A significant difference in the immobility time among the groups was found in the FST (Fig. $2 \mathrm{~F}$ and $\mathrm{G} ; F_{2}, 33=5.55, P=0.008$ ). $\mathrm{BCCAO}+$ veh group presented increased immobility in the FST compared with the sham + veh group $(P=0.05)$. BAY $60-7550$ decreased immobility in BCCAO animals compared to BCCAO + veh animals $(P=0.0005)$. No differences were detected in latency to the first immobility episode between the experimental groups $\left(F_{2,33}=1.49, P=0.23\right)$.

\section{BAY 60-7550 attenuates the decrease in NeuN and increase activated caspase- 9 protein levels in the hippocampus of BCCAO mice}

Western blot analysis revealed differences in the protein levels of NeuN in the hippocampus $\left(\chi^{2}=10.86, P=0.004\right.$, Fig. 3$)$. BCCAO mice showed a decrease in the NeuN protein levels compared to 

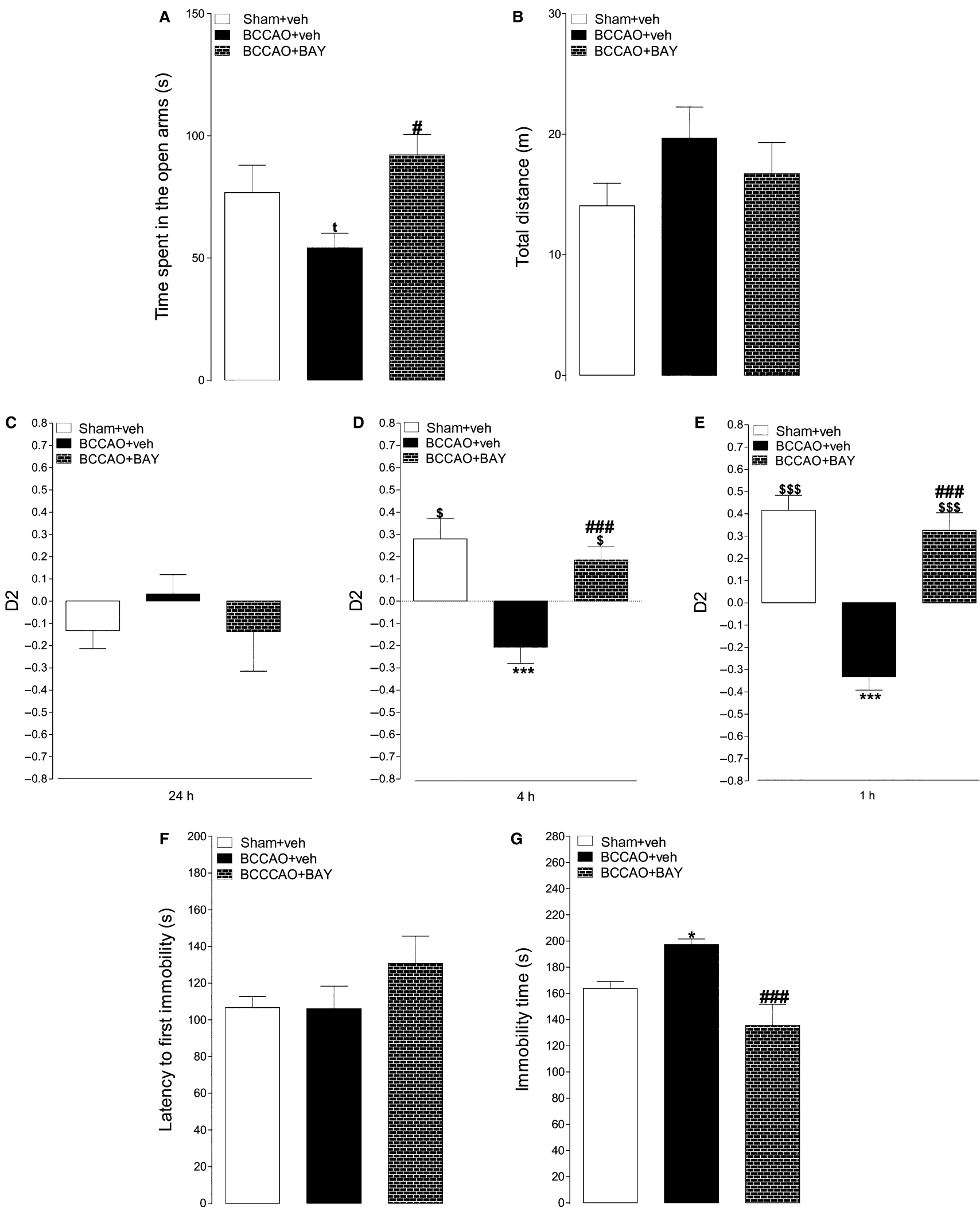

FIG. 2. BAY 60-7550 ameliorates cognitive and emotional impairments in BCCAO mice. (A) Time spent in the open arms of EZM. (B) Total distance in the OF. (C-E) Discrimination index (D2) at 24, 4, and $1 \mathrm{~h}$ intervals in the OLT. (F-G) Latency to first immobility and immobility time in the FST. Bars represent the means \pm SEM per experimental group. sham + veh $(n=12)$; BCCAO + veh $(n=11)$, BCCAO + BAY $(n=11)$. ${ }^{\mathrm{t} P}<0.1$ compared to the $\mathrm{BCCAO}+$ veh group. ${ }^{*} P<0.05,{ }^{* *} P<0.01$ and ${ }^{* * *} P<0.001$ compared to the sham + veh group. ${ }^{\#} P<0.05$, ${ }^{\# \#} P<0.01$ and ${ }^{\# \# \#} P<0.001$ compared to the BCCAO + veh group (ANOva followed by the Tukey's test). ${ }^{\$} P<0.05$ and ${ }^{\$ \$} P<0.0001$ compared to zero, i.e., chance level $=$ no memory (one-sample $t$-test). EZM, elevated zero maze; OF, open field; OLT, object location test; FST, forced swim test. 
A
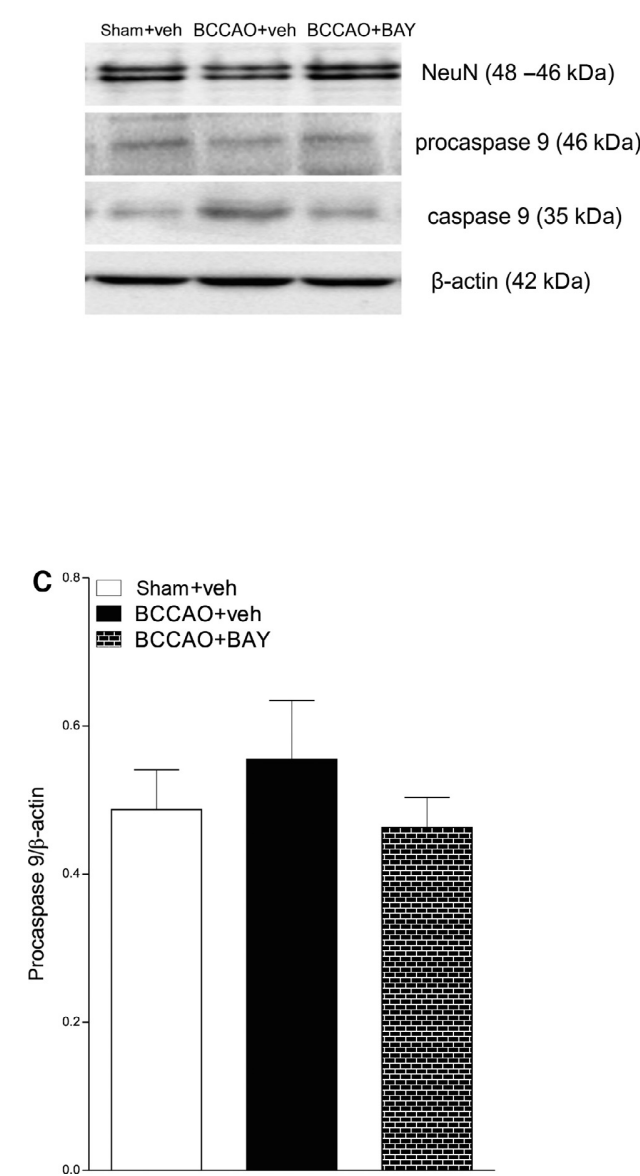
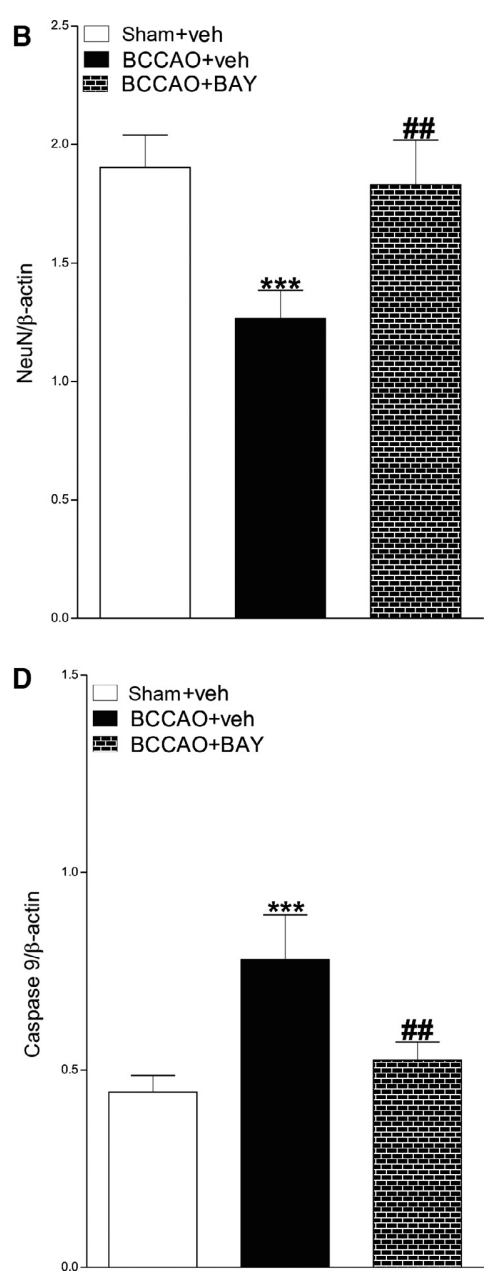

FIG. 3. BAY 60-7550 attenuates the decrease in NeuN and increase in activated Caspase-9 protein levels in the hippocampus of BCCAO mice. (A) Representative western blots of NeuN, procaspase-9 and activated caspase-9 protein levels. (B-D) Quantification of western blots in (A) was performed via densitometric analysis and is presented as a percentage of control, normalized to $\beta$-actin. Bars represent the means \pm SEM per experimental group. Sham + veh $(n=6)$; $\mathrm{BCCAO}+$ veh $(n=6)$, BCCAO + BAY $(n=6) .{ }^{* * *} P<0.001$ compared to the sham + veh group. ${ }^{\# \#} P<0.01$ compared to the BCCAO + veh group.

sham + veh group $(P=0.0006)$. BAY 60-7550 increased the NeuN protein levels in BCCAO mice compared to BCCAO + veh group $(P=0.001)$. Furthermore, alterations of activated form of caspase-9 was found $\left(\chi^{2}=12.40, P=0.002\right.$, Fig. 3$)$. BCCAO mice presented higher protein levels of caspase-9 than sham + veh mice $(P=0.0001)$. On the other hand, BCCAO mice treated with BAY 60-7550 showed a decrease in the expression of caspase- 9 compared to BCCAO + veh group $(P=0.006)$. No difference was found in the expression of procaspase-9 $\left(\chi^{2}=1.57, P=0.4\right)$.

\section{BAY 60-7550 enhances hippocampal expression of pCREB in BCCAO mice}

As shown in Fig. 4, it was detected significant differences in the pCREB-IR in the CA1 $\left(\chi^{2}=7.36, P=0.02\right)$, CA3 $\left(\chi^{2}=9.70\right.$, $P=0.007)$ and DG $\left(\chi^{2}=3.63, P=0.04\right.$, Fig. 4B). In general, $\mathrm{BCCAO}+\mathrm{BAY}$ mice showed an increased in pCREB-IR compared to sham + veh (CA1, $P=0.007 ;$ CA3, $P=0.001)$ and $\mathrm{BCCAO}+\mathrm{veh} \quad(\mathrm{CA} 3, \quad P=0.008$ and $\mathrm{DG}, \quad P=0.04)$ animals.

\section{$B A Y 60-7550$ restores BDNF protein levels in the hippocampus of BCCAO mice}

Differences in the protein levels of mature BDNF were also detected in the hippocampus $\left(\chi^{2}=8.43, P=0.01\right.$, Fig. 5$)$. BCCAO + veh mice showed a decreased in the level of BDNF compared to sham + veh group $(P=0.003)$. BAY $60-7550$ increased the level of BDNF in $\mathrm{BCCAO}$ mice compared to BCCAO $+\operatorname{veh}$ group $(P=0.03)$.

\section{Discussion}

The present study found that BCCAO increased anxiety-like behavior, impaired hippocampus-dependent cognitive function, and increased despair-like behavior in mice. BCCAO also caused hippocampal neurodegeneration, reflected by a decrease in NeuN and an increase in activated caspase- 9 protein levels in the hippocampus. A decrease in BDNF protein levels was also detected in BCCAO mice compared with controls. BAY 60-7550 administration for 21 days attenuated the cognitive and affective impairments that were induced by brain ischemia, promoted hippocampal neuroprotection, and enhanced BDNF and pCREB expression in the hippocampus in BCCAO mice. These findings support a neuroprotective role for PDE2-I in conditions of brain ischemia. 

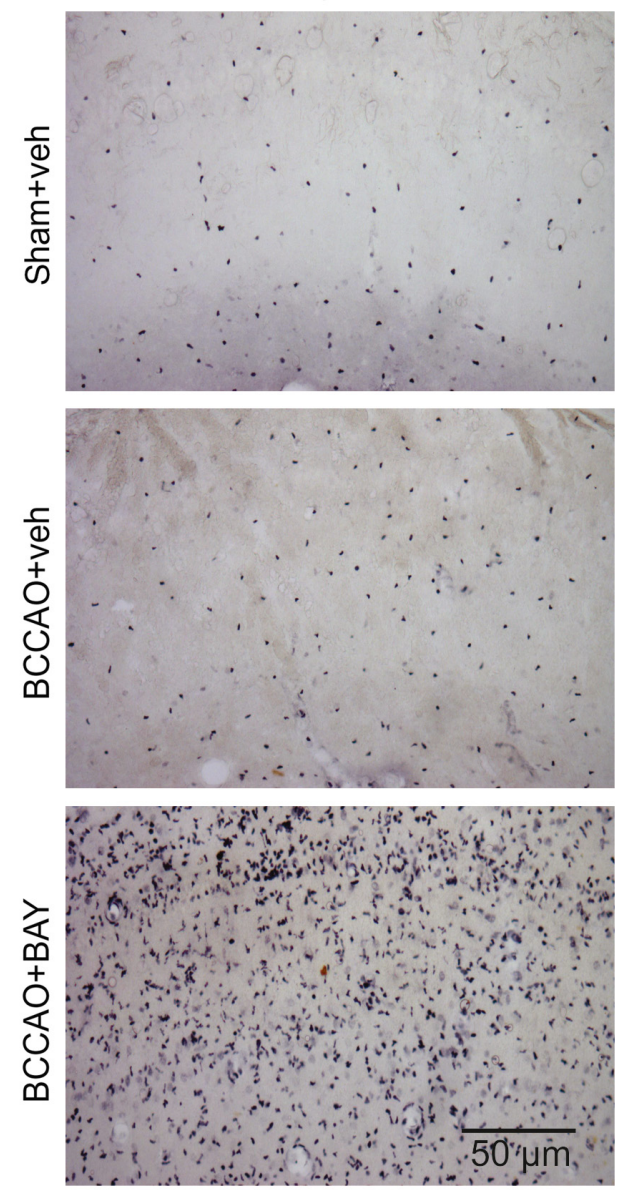

CA3
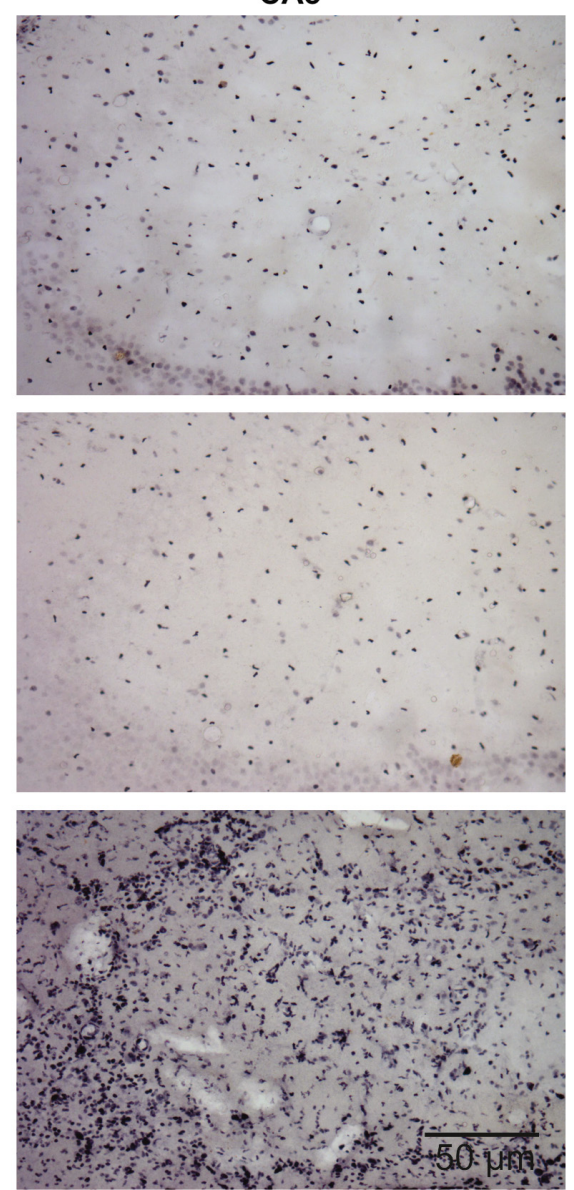

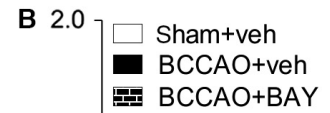

뫂 $\mathrm{BCCAO}+\mathrm{BAY}$

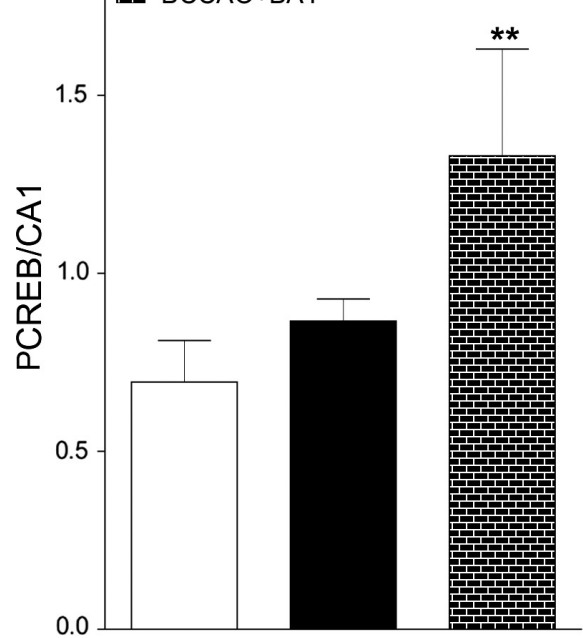

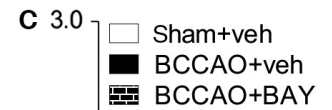

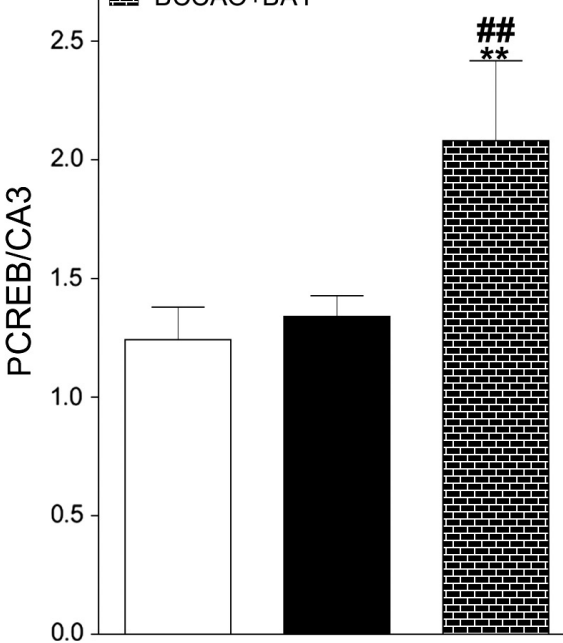

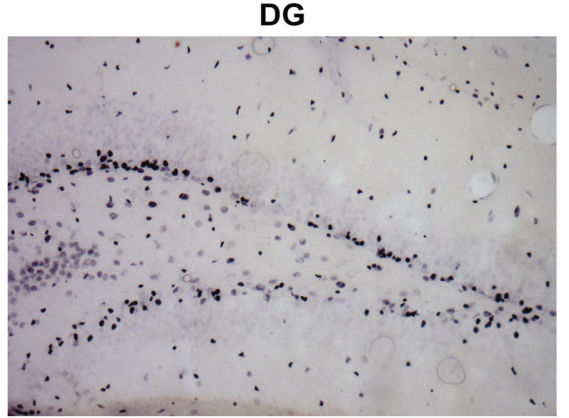
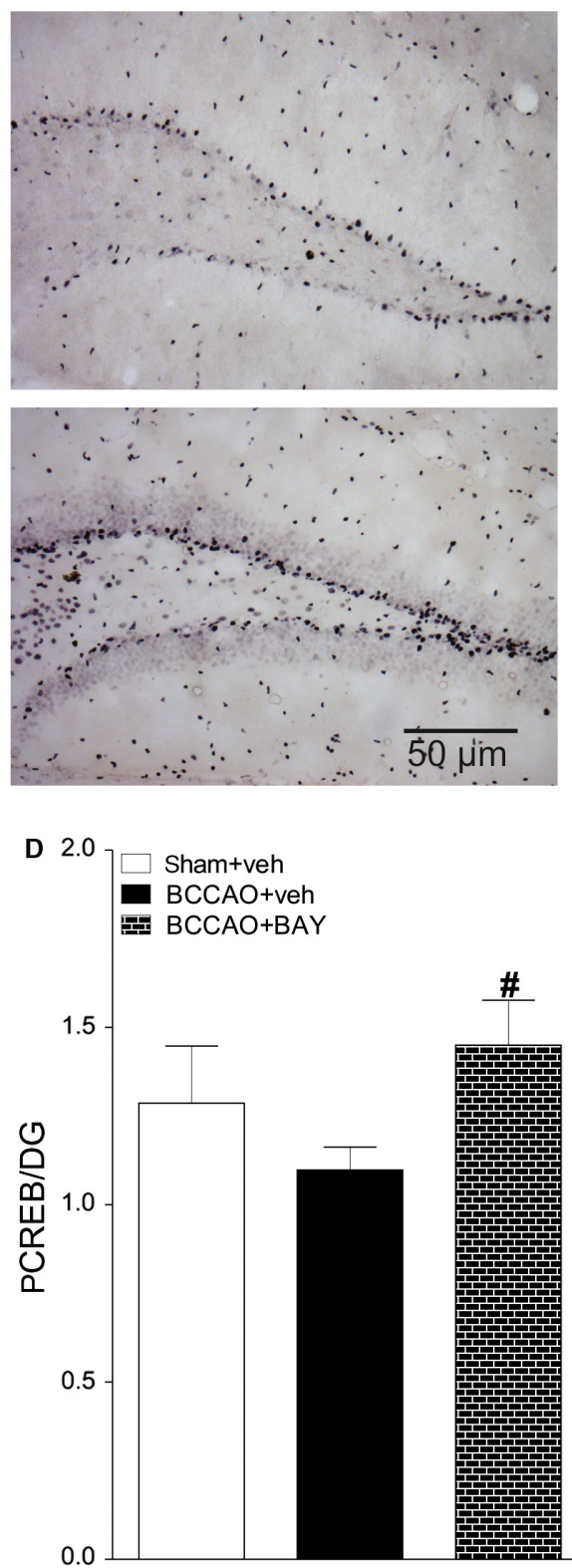

FIG. 4. BAY 60-7550 enhances hippocampal expression of pCREB in BCCAO mice. (A) Representative pictures of immunohistochemical stainings and (C-E) immunohistochemical analysis for pCREB immunoreactivity in the CA1, CA3 and DG of hippocampus respectively. Bars represent mean \pm SEM per experimental group. sham + veh $(n=6)$; BCCAO + veh $(n=5)$, BCCAO + BAY $(n=5) .{ }^{*} P<0.05,{ }^{* *} P<0.01$, and $* * * P<0.001$ compared to the sham + veh

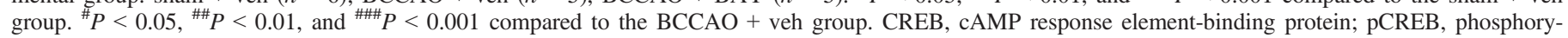
lated CREB; DG, dentate gyrus. [Colour figure can be viewed at wileyonlinelibrary.com].

Ischemic mice exhibited a decrease in the time spent in the open arms of the EZM 7 days after reperfusion, reflecting BCCAOinduced anxiogenic-like behavior. The selective PDE2-I BAY 60-
7550 produced anxiolytic-like effects in BCCAO mice. Our results are consistent with previous studies that reported anxiolytic-like effects of BAY 60-7550 in mice in the elevated plus maze, open 
A Sham+veh BCCAO+veh BCCAO+BAY
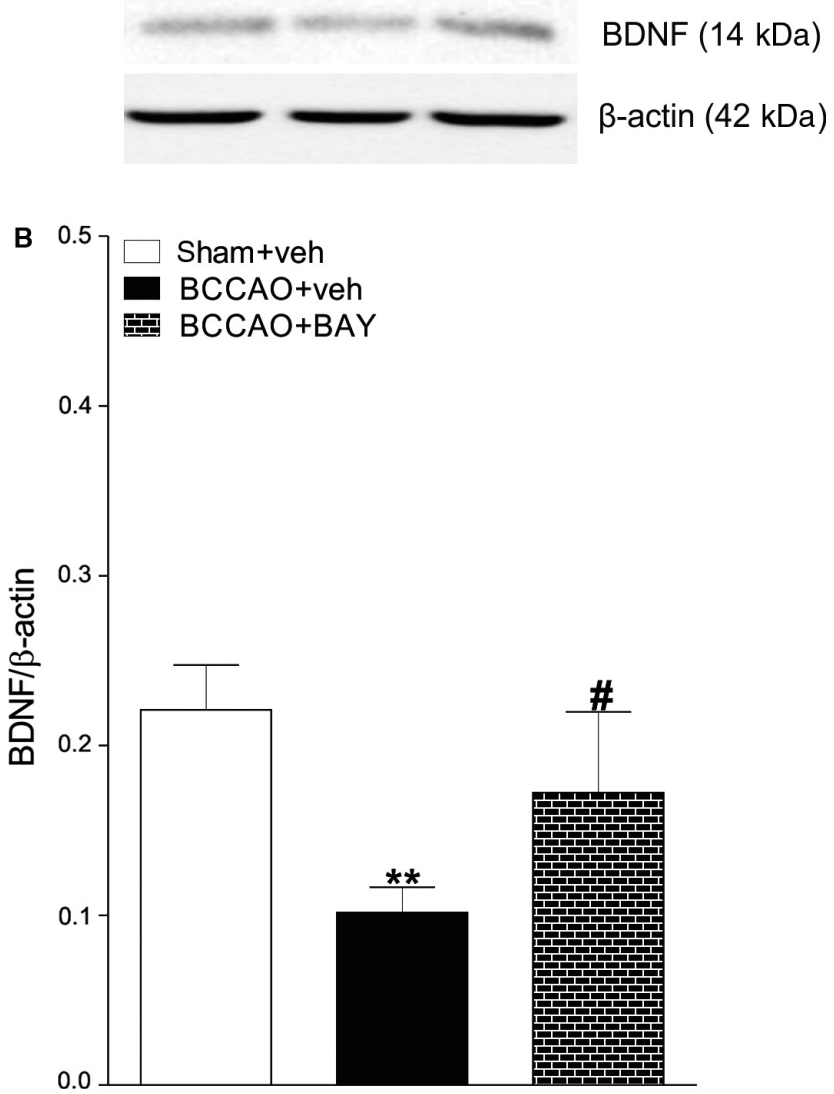

FIG. 5. BAY 60-7550 restores BDNF protein levels in the hippocampus of BCCAO mice. (A) Representative western blots of BDNF protein levels. (B) Quantification of western blots in (A) was performed by densitometric analysis and is presented as a percentage of control, normalized to $\beta$ - actin. Bars represent mean \pm SEM per experimental group. sham + veh $(n=6)$; $\mathrm{BCCAO}+$ veh $(n=6), \mathrm{BCCAO}+\mathrm{BAY}(n=6) .{ }^{* *} P<0.01$ compared to the sham + veh group. ${ }^{\#} P<0.05$ compared to the BCCAO + veh group. $\mathrm{BDNF}$, brain-derived neurotrophic factor.

field test, and holeboard test (Masood et al., 2008, 2009). In these studies, pretreatment with BAY 60-7550 reversed both buthionine$(S, R)$-sulfoximine-induced oxidative stress and the anxiogenic-like effects on behavior. Additionally, pretreatment with the guanylyl cyclase inhibitor $1 H$-[1,2,4]oxadiazolo[4,3-a]quinoxalin-1-one (ODQ) inhibited the anxiolytic-like effects of BAY, indicating that the behavioral effects of this PDE2-I depended on an increase in cGMP levels (Masood et al., 2008, 2009). However, conflicting results have been reported from behavioral studies with regard to the activation of cGMP and its mediator nitric oxide (NO), which has been shown to induce either anxiolytic- or anxiogenic-like behavior. The majority of findings suggest that inhibition of the NO-cGMP pathway is anxiolytic, whereas its activation is anxiogenic (Volke et al., 1997, 2003; Guimaraes et al., 2005). Other studies have reported opposite findings (De Oliveira et al., 1997; Vale et al., 1998; Solis et al., 2008) or even dual effects of NOcGMP pathway inhibitors (Spiacci et al., 2008). Indeed, the effects of drugs on NO-cGMP pathways are complex and may vary, depending on the treatment regimen (e.g., acute vs. chronic), dose, and functional state of target neurons (Contestabile, 2000). Furthermore, activation of the NO-cGMP pathway may interfere with the release of several neurotransmitters in the brain. The cGMP-selective PDE5-I sildenafil acutely increased anxiety, but chronic administration had anxiolytic effects and involved a cholinergic interaction (Liebenberg et al., 2012). Moreover, cGMP may not be the only mediator of the anxiety-related behavioral effects of BAY 60-7550; cAMP might also play an important role because PDE2 responds to elevations of cGMP levels, resulting in an increase in the hydrolysis of cAMP (Murashima et al., 1990). Therefore, PDE2 has been suggested to be a link between cAMP- and cGMPmediated signaling mechanisms (Hajjhussein et al., 2007). Whether such mechanisms are involved in the anxiolytic-like effects of BAY $60-7550$ in the ischemic brain remains to be tested.

In the present study, impairments in hippocampus-dependent cognitive function were detected in ischemic mice in the OLT that were tested at 1 and $4 \mathrm{~h}$ intervals. PDE2 inhibition improved performance in BCCAO mice in the OLT, demonstrating the memory-enhancing potential of BAY60-7550. Our findings corroborate other studies that reported that BAY 60-7550 enhanced memory in adult and aged rats and mice (Boess et al., 2004; Domek-Lopacinska \& Strosznajder, 2008), reversed scopolamine- and MK-801-induced object recognition memory deficits (Reneerkens et al., 2013), improved memory in the APPswe/PS1dE9 mouse model of Alzheimer's disease (Sierksma et al., 2013), and ameliorated cognitive impairments in stressed mice (Xu et al., 2015).

Persistent memory deficits that are caused by BCCAO are associated with significant neuronal loss in the hippocampus, cerebral cortex, and amygdala (Yang et al., 1997; Yoshioka et al., 2011; Soares et al., 2016). We found that $20 \mathrm{~min}$ of BCCAO decreased hippocampal NeuN protein levels, an indication of hippocampal neurodegeneration. This was further supported by the fact that BCCAO mice expressed higher levels of activated caspase- 9 compared with controls. Caspase-9 activation is an important initial step in activation of the mitochondria-dependent intrinsic apoptosis-signaling pathway (Li et al., 1997). An intracerebral infusion of the specific caspase-9 inhibitor $N$-benzyloxycarbonyl-Leu-Glu-His-Asp-fluoromethylketone before the onset of ischemia significantly enhanced neuronal survival in CA1 pyramidal neurons in a rat model of transient global brain ischemia (Cao et al., 2002). In the present study, BAY 60-7550 decreased the hippocampal expression of activated caspase- 9 and enhanced the hippocampal expression of NeuN protein in BCCAO mice. Moreover, anti-apoptotic effects of BAY607550 have been previously proposed in chronically stressed mice (Ding et al., 2014).

Previous studies have demonstrated that treatment with BAY 607550 influenced depressive-like behaviors that were induced by chronic unpredictable stress (CUS) in mice. Ding et al. (2014) showed that repeated treatment with BAY60-7550 in stressed mice resulted in anxiolytic- and antidepressant-like effects that were comparable to diazepam and desipramine respectively. The behavioral effects of BAY 60-7550 involved regulation between pro-/anti-apoptotic mechanisms, reflected by a decrease in BAX and caspase-3 expression (i.e., pro-apoptosis) with a concomitant increase in Bcl-2 expression (i.e., anti-apoptosis) in the hippocampus (Ding et al., 2014). An antioxidant effect of BAY has also been proposed. The present study found that PDE2 inhibition produced antidepressantlike effects in BCCAO mice, reflected by a reduction in immobility time in the FST. Interestingly, PDE2 is also expressed in the adrenal glands (Nikolaev et al., 2005), which are part of the hypothalamicpituitary-adrenal axis, making PDE2 a likely mediator of stressinduced affective behaviors (Masood et al., 2008). The inhibition of adrenal PDE2 might have contributed to the antidepressant-like effects of BAY 60-7550 in ischemic mice.

The beneficial effects of PDE2 inhibition on brain ischemic conditions could be explained by activation of both the cAMP/PKA/ 
CREB and cGMP/PKG/CREB pathways, which leads to CREB phosphorylation and consequently de novo protein synthesis (Rutten et al., 2009). Here, repeated BAY 60-7550 administration enhanced the hippocampal expression pCREB in BCCAO mice compared with controls. In agreement, $\mathrm{Xu}$ et al. (2015) reported that chronic BAY 60-7550 treatment significantly reversed the chronic unpredictable stress-induced decrease in the hippocampal expression of pCREB in mice. CREB is an essential factor in the regulation of BDNF expression (Shieh \& Ghosh, 1999) which has been involved in memory-enhancing and antidepressant-like effects (Cirulli et al., 2004) effects. BDNF also plays a critical role in neural repair processes (Ploughman et al., 2009) and hippocampal neurogenesis (Sasaki et al., 2007). Experimental studies have shown that intracerebroventricular BDNF infusion prevented neuronal death in the vulnerable CA1 region of the hippocampus and improved long-term potentiation and cognitive function after brain ischemia in rats (Kiprianova et al., 1999). Moreover, chronic PDE3-I and PDE4-I treatment induced higher BDNF protein levels in the hippocampus and promoted the recovery of neurological deficits in ischemic mice (Lee et al., 2004; Shin et al., 2010; Tanaka et al., 2010). We found that repeated BAY 60-7550 treatment restored hippocampal BDNF expression in BCCAO mice. To our knowledge, this is the first study that assessed the effects of chronic PDE2 inhibition on BDNF levels in the hippocampus in BCCAO mice.

An increase in the BDNF hippocampal levels in response to activation of cAMP-CREB signaling has been related to functional recovery (Clarkson et al., 2015; Zhao et al., 2015). and survival of newborn neurons after brain ischemia (Sasaki et al., 2007). We have previously shown that rolipram, a selective PDE3-I which hydrolises cAMP, attenuated the behavioral effects and decreased hippocampal neurodegeneration induced by BCCAO in mice. Rolipram also increased the dendrite extension and ramification of newborn neurons and the expression of MAP-2, a protein related to the structural integrity of the neuronal cytoskeleton, in the hippocampus of BCCAO animals (Soares et al., 2016). Altogether, these findings indicate that pharmacological activation of cAMP-CREB signaling may provide a therapeutic approach for the treatment of brain ischemia.

An important point to consider in the present study is the poor pharmacokinetic properties of BAY 60-7550 (Gomez \& Breitenbucher, 2013). A recent study found that the brain concentration of BAY 60-7750 was below the limit of detection $30 \mathrm{~min}$ after oral administration of a $1 \mathrm{mg} / \mathrm{kg}$ dose, indicating the possible lack of clear penetration of BAY 60-7550 into the brain (Reneerkens et al., 2013). However, brain ischemia results in disruption of the bloodbrain barrier (Sadoshima et al., 1986), thus increasing the permeability to drugs. Such an effect on the blood-brain barrier may have contributed to our observed effects of BAY 60-7550 in BCCAO mice.

Our study extends previous findings by demonstrating that PDE inhibition may be beneficial in ischemic conditions by decreasing neurodegeneration and stimulating plasticity in the hippocampus of BCCAO mice. The present study provides evidence of the potential use of PDE2-Is against brain ischemic injury. Repeated BAY 607550 treatment prevented functional impairments that were induced by BCCAO in mice. These effects could be partially attributable to the anti-apoptotic and neuroplastic effects of BAY 60-7550. PDE2 inhibition decreased the expression of activated caspase- 9 and simultaneously increased the concentrations of NeuN, CREB, pCREB, and BDNF in the hippocampus in BCCAO mice. Further research is needed to clarify whether additional mechanisms could account for the beneficial behavioral effects of chronic PDE2 inhibition in brain ischemia.

\section{Conflict of interest}

The authors declare no conflict of interest.

\section{Acknowledgments}

The authors thank Marco Alberto Trombelli and Jailson Araújo Dantas for their technical support. This study was supported by Conselho Nacional de Desenvolvimento Científico e Tecnológico (CNPq), Universidade Estadual de Maringá, The University of Maastricht and CAPES/NUFFIC 1608/2010, Brazil.

\section{Abbreviations}

BAY, 60-7550, 2-[3,4-dimethoxybenzyl]-7-\{(1R)-1-[(1R)-1-hydroxyethyl]-4phenylbutyl $\}$-5-methylimidazo[5,1-f][1,2,4]triazin-4[3H]-one; BCCAO, bilateral common carotide artery occlusion; BDNF, brain-derived neurotrophic factor; BSA, bovine serum albumine; cAMP, cyclic adenosine monophosphate; cGMP, cyclic guanosine monophosphate; CREB, cAMP response element-binding protein; EZM, elevated zero maze; FST, forced swim test; i.p., intraperitoneal; IOD, integrated optical density; IR, immunoreactivity; NeuN, neuronal nuclei; NO, nitric oxide; ODQ, $1 H$-[1,2,4] oxadiazolo[4,3-a]quinoxalin-1-one; OLT, object location test; p.o. per os; PB, phosphate buffer; PBS, phosphate buffer saline; pCREB, phosphorylated CREB; PDE, phosphodiesterase; PDE2-I, phosphodiesterase inhibitor 2 inhibitor; PDEI, phosphodiesterase inhibitor; PKA, protein kinase A; PKG, protein kinase G.

\section{References}

Akkerman, S., Blokland, A., Reneerkens, O., van Goethem, N.P., Bollen, E., Gijselaers, H.J., Lieben, C.K., Steinbusch, H.W. et al. (2012) Object recognition testing: methodological considerations on exploration and discrimination measures. Behav. Brain Res., 232, 335-347.

Berton, O. \& Nestler, E.J. (2006) New approaches to antidepressant drug discovery: beyond monoamines. Nat. Rev. Neurosci., 7, 137-151.

Boess, F.G., Hendrix, M., van der Staay, F.J., Erb, C., Schreiber, R., van Staveren, W., de Vente, J., Prickaerts, J. et al. (2004) Inhibition of phosphodiesterase 2 increases neuronal cGMP, synaptic plasticity and memory performance. Neuropharmacology, 47, 1081-1092.

Bollen, E., Puzzo, D., Rutten, K., Privitera, L., De Vry, J., Vanmierlo, T., Kenis, G., Palmeri, A. et al. (2014) Improved long-term memory via enhancing cGMP-PKG signaling requires cAMP-PKA signaling. Neuropsychopharmacol., 39, 2497-2505.

Cao, G., Luo, Y., Nagayama, T., Pei, W., Stetler, R.A., Graham, S.H. \& Chen, J. (2002) Cloning and characterization of rat caspase-9: implications for a role in mediating caspase-3 activation and hippocampal cell death after transient cerebral ischemia. J. Cerebr. Blood F. Met., 22, 534-546.

Cirulli, F., Berry, A., Chiarotti, F. \& Alleva, E. (2004) Intrahippocampal administration of BDNF in adult rats affects short-term behavioral plasticity in the Morris water maze and performance in the elevated plus-maze. Hippocampus, 14, 802-807.

Clarkson, A.N., Parker, K., Nilsson, M., Walker, F.R. \& Gowing, E.K. (2015) Combined ampakine and BDNF treatments enhance poststroke functional recovery in aged mice via AKT-CREB signaling. J. Cerebr. Blood F. Met., 35, 1272-1279.

Contestabile, A. (2000) Roles of NMDA receptor activity and nitric oxide production in brain development. Brain Res. Brain Res. Rev., 32, 476-509.

Conti, M. \& Beavo, J. (2007) Biochemistry and physiology of cyclic nucleotide phosphodiesterases: essential components in cyclic nucleotide signaling. Annu. Rev. Biochem., 76, 481-511.

De Oliveira, C.L., Del Bel, E.A. \& Guimaraes, F.S. (1997) Effects of LNOARG on plus-maze performance in rats. Pharmacol. Biochem. Be., 56, 55-59.

Ding, L., Zhang, C., Masood, A., Li, J., Sun, J., Nadeem, A., Zhang, H.T., O'Donnell, J.M. et al. (2014) Protective effects of phosphodiesterase 2 inhibitor on depression- and anxiety-like behaviors: involvement of antioxidant and anti-apoptotic mechanisms. Behav. Brain Res., 268, 150-158.

Domek-Lopacinska, K. \& Strosznajder, J.B. (2008) The effect of selective inhibition of cyclic GMP hydrolyzing phosphodiesterases 2 and 5 on learning and memory processes and nitric oxide synthase activity in brain during aging. Brain Res., 1216, 68-77.

Franklin, K.B.J. \& Paxinos, G. (1997). The Mouse Brain in Stereotaxic Coordinates, 2nd edn. Academic Press, San Diego, CA. 
Geri, G., Mongardon, N., Daviaud, F., Empana, J.P., Dumas, F. \& Cariou, A. (2014) Neurological consequences of cardiac arrest: where do we stand? Ann. Fr. Anesth., 33, 98-101.

Gomez, L. \& Breitenbucher, J.G. (2013) PDE2 inhibition: potential for the treatment of cognitive disorders. Bioorg. Med. Chem. Lett., 23, 65226527.

Guimaraes, F.S., Beijamini, V., Moreira, F.A., Aguiar, D.C. \& de Lucca, A.C. (2005) Role of nitric oxide in brain regions related to defensive reactions. Neurosci. Biobehav. R., 29, 1313-1322.

Hajjhussein, H., Suvarna, N.U., Gremillion, C., Chandler, L.J. \& O’Donnell, J.M. (2007) Changes in NMDA receptor-induced cyclic nucleotide synthesis regulate the age-dependent increase in PDE4A expression in primary cortical cultures. Brain Res., 1149, 58-68.

Heckman, P.R., van Duinen, M.A., Bollen, E.P., Nishi, A., Wennogle, L.P., Blokland, A. \& Prickaerts, J. (2016) Phosphodiesterase inhibition and regulation of dopaminergic frontal and striatal functioning: clinical implications. Int. J. Neuropsychop., 19, 1-16.

Hu, S., Cao, Q., Xu, P., Ji, W., Wang, G. \& Zhang, Y. (2016) Rolipram stimulates angiogenesis and attenuates neuronal apoptosis through the cAMP/cAMP-responsive element binding protein pathway following ischemic stroke in rats. Exp. Ther. Med., 11, 1005-1010.

Kanterewicz, B.I., Urban, N.N., McMahon, D.B., Norman, E.D., Giffen, L.J., Favata, M.F., Scherle, P.A., Trzskos, J.M. et al. (2000) The extracellular signal-regulated kinase cascade is required for NMDA receptor-independent LTP in area CA1 but not area CA3 of the hippocampus. J. Neurosci., 20, 3057-3066

Kim, Y.R., Kim, H.N., Hong, K.W., Shin, H.K. \& Choi, B.T. (2016) Antidepressant effects of phosphodiesterase 3 inhibitor cilostazol in chronic mild stress-treated mice after ischemic stroke. Psychopharmacology, 233, $1055-1066$.

Kiprianova, I., Sandkuhler, J., Schwab, S., Hoyer, S. \& Spranger, M. (1999) Brain-derived neurotrophic factor improves long-term potentiation and cognitive functions after transient forebrain ischemia in the rat. Exp. Neurol., 159, 511-519.

Lee, T.H., Yang, J.T., Kato, H., Wu, J.H. \& Chen, S.T. (2004) Expression of brain-derived neurotrophic factor immunoreactivity and mRNA in the hippocampal CA1 and cortical areas after chronic ischemia in rats. J. Neurosci. Res., 76, 705-712.

Li, P., Nijhawan, D., Budihardjo, I., Srinivasula, S.M., Ahmad, M., Alnemri, E.S. \& Wang, X. (1997) Cytochrome c and dATP-dependent formation of Apaf-1/caspase-9 complex initiates an apoptotic protease cascade. Cell, 91, 479-489.

Li, Y.F., Huang, Y., Amsdell, S.L., Xiao, L., O’Donnell, J.M. \& Zhang, H.T. (2009) Antidepressant- and anxiolytic-like effects of the phosphodiesterase-4 inhibitor rolipram on behavior depend on cyclic AMP response element binding protein-mediated neurogenesis in the hippocampus. Neuropsychopharmacol., 34, 2404-2419.

Liebenberg, N., Harvey, B.H., Brand, L., Wegener, G. \& Brink, C.B. (2012) Chronic treatment with the phosphodiesterase type 5 inhibitors sildenafil and tadalafil display anxiolytic effects in Flinders Sensitive Line rats. Metab. Brain Dis., 27, 337-340.

Masood, A., Nadeem, A., Mustafa, S.J. \& O’Donnell, J.M. (2008) Reversal of oxidative stress-induced anxiety by inhibition of phosphodiesterase-2 in mice. J. Pharmacol. Exp. Ther., 326, 369-379.

Masood, A., Huang, Y., Hajjhussein, H., Xiao, L., Li, H., Wang, W., Hamza, A., Zhan, C.G. et al. (2009) Anxiolytic effects of phosphodiesterase-2 inhibitors associated with increased cGMP signaling. J. Pharmacol. Exp. Ther., 331, 690-699.

Matsumoto, Y., Unoki, S., Aonuma, H. \& Mizunami, M. (2006) Critical role of nitric oxide-cGMP cascade in the formation of cAMP-dependent longterm memory. Learn Memory, 13, 35-44.

Maurice, D.H., Ke, H., Ahmad, F., Wang, Y., Chung, J. \& Manganiello, V.C. (2014) Advances in targeting cyclic nucleotide phosphodiesterases. Nat. Rev. Drug Discov., 13, 290-314.

Moretti, R., Leger, P.L., Besson, V.C., Csaba, Z., Pansiot, J., Di Criscio, L., Gentili, A., Titomanlio, L. et al. (2016) Sildenafil, a cyclic GMP phosphodiesterase inhibitor, induces microglial modulation after focal ischemia in the neonatal mouse brain. J. Neuroinflamm., 13, 95.

Moulaert, V.R., Wachelder, E.M., Verbunt, J.A., Wade, D.T. \& van Heugten, C.M. (2010) Determinants of quality of life in survivors of cardiac arrest. J. Rehabil. Med., 42, 553-558.

Murashima, S., Tanaka, T., Hockman, S. \& Manganiello, V. (1990) Characterization of particulate cyclic nucleotide phosphodiesterases from bovine brain: purification of a distinct cGMP-stimulated isoenzyme. Biochemistry, 29, 5285-5292.
Nikolaev, V.O., Gambaryan, S., Engelhardt, S., Walter, U. \& Lohse, M.J. (2005) Real-time monitoring of the PDE2 activity of live cells: hormonestimulated cAMP hydrolysis is faster than hormone-stimulated cAMP synthesis. J. Biol. Chem., 280, 1716-1719.

Ploughman, M., Windle, V., MacLellan, C.L., White, N., Dore, J.J. \& Corbett, D. (2009) Brain-derived neurotrophic factor contributes to recovery of skilled reaching after focal ischemia in rats. Stroke, 40, 1490-1495.

Porsolt, R.D., Anton, G., Blavet, N. \& Jalfre, M. (1978) Behavioural despair in rats: a new model sensitive to antidepressant treatments. Eur. J. Pharmacol., 47, 379-391.

Reneerkens, O.A., Rutten, K., Steinbusch, H.W., Blokland, A. \& Prickaerts, J. (2009) Selective phosphodiesterase inhibitors: a promising target for cognition enhancement. Psychopharmacology, 202, 419-443.

Reneerkens, O.A., Rutten, K., Bollen, E., Hage, T., Blokland, A., Steinbusch, H.W. \& Prickaerts, J. (2013) Inhibition of phoshodiesterase type 2 or type 10 reverses object memory deficits induced by scopolamine or MK-801. Behav. Brain Res., 236, 16-22.

Rodefer, J.S., Saland, S.K. \& Eckrich, S.J. (2012) Selective phosphodiesterase inhibitors improve performance on the ED/ID cognitive task in rats. Neuropharmacology, 62, 1182-1190.

Rutten, K., Van Donkelaar, E.L., Ferrington, L., Blokland, A., Bollen, E., Steinbusch, H.W., Kelly, P.A. \& Prickaerts, J.H. (2009) Phosphodiesterase inhibitors enhance object memory independent of cerebral blood flow and glucose utilization in rats. Neuropsychopharmacol., 34, 1914 1925.

Sadoshima, S., Fujii, K., Yao, H., Kusuda, K., Ibayashi, S. \& Fujishima, M. (1986) Regional cerebral blood flow autoregulation in normotensive and spontaneously hypertensive rats-effects of sympathetic denervation. Stroke, 17, 981-984.

Sallustio, F. \& Studer, V. (2016) Targeting new pharmacological approaches for Alzheimer's disease: potential for statins and phosphodiesterase inhibitors. CNS Neurol. Disord. Dr., 15, 647-659.

Sasaki, T., Kitagawa, K., Omura-Matsuoka, E., Todo, K., Terasaki, Y., Sugiura, S., Hatazawa, J., Yagita, Y. et al. (2007) The phosphodiesterase inhibitor rolipram promotes survival of newborn hippocampal neurons after ischemia. Stroke, 38, 1597-1605.

Shepherd, J.K., Grewal, S.S., Fletcher, A., Bill, D.J. \& Dourish, C.T. (1994) Behavioural and pharmacological characterisation of the elevated "zero-maze" as an animal model of anxiety. Psychopharmacology, 116, $56-64$.

Shieh, P.B. \& Ghosh, A. (1999) Molecular mechanisms underlying activity-dependent regulation of BDNF expression. J. Neurobiol., 41, 127134.

Shim, S., Shuman, M. \& Duncan, E. (2016) An emerging role of cGMP in the treatment of schizophrenia: a review. Schizophr. Res., 170, 226-231.

Shin, H.K., Lee, H.R., Lee, D.H., Hong, K.W., Lee, J.H., Park, S.Y., Lee, S.J., Lee, J.S. et al. (2010) Cilostazol enhances neovascularization in the mouse hippocampus after transient forebrain ischemia. J. Neurosci. Res., 88, 2228-2238.

Sierksma, A.S., Rutten, K., Sydlik, S., Rostamian, S., Steinbusch, H.W., van den Hove, D.L. \& Prickaerts, J. (2013) Chronic phosphodiesterase type 2 inhibition improves memory in the APPswe/PS1dE9 mouse model of Alzheimer's disease. Neuropharmacology, 64, 124-136.

Soares, L.M., Prickaerts, J., Milani, H., Del Bel, E., Steinbusch, H.W. \& de Oliveira, R.M. (2015) Phosphodiesterase inhibition as a therapeutic target for brain ischemia. CNS Neurol. Disord. Dr., 14, 1012-1023.

Soares, L.M., De Vry, J., Steinbusch, H.W., Milani, H., Prickaerts, J. \& Weffort de Oliveira, R.M. (2016) Rolipram improves cognition, reduces anxiety- and despair-like behaviors and impacts hippocampal neuroplasticity after transient global cerebral ischemia. Neuroscience, 326, 69-83.

Solis, A.A., Bethancourt, J.A. \& Britton, G.B. (2008) Chronic sildenafil (Viagra) administration reduces anxiety in intact and castrated male rats. Psicothema, 20, 812-817.

Spiacci, A. Jr, Kanamaru, F., Guimaraes, F.S. \& Oliveira, R.M. (2008) Nitric oxide-mediated anxiolytic-like and antidepressant-like effects in animal models of anxiety and depression. Pharmacol. Biochem. Be., 88, 247-255.

Su, T., Zhang, T., Xie, S., Yan, J., Wu, Y., Li, X., Huang, L. \& Luo, H.B. (2016) Discovery of novel PDE9 inhibitors capable of inhibiting Abeta aggregation as potential candidates for the treatment of Alzheimer's disease. Sci. Rep., 6, 21826.

Takagi, T. \& Hara, H. (2016) Protective effects of cilostazol against hemorrhagic stroke: current and future perspectives. J. Pharmacol. Sci., 131, $155-161$.

Tanaka, Y., Tanaka, R., Liu, M., Hattori, N. \& Urabe, T. (2010) Cilostazol attenuates ischemic brain injury and enhances neurogenesis in the 
subventricular zone of adult mice after transient focal cerebral ischemia. Neuroscience, 171, 1367-1376.

Trabanco, A.A., Buijnsters, P. \& Rombouts, F.J. (2016) Towards selective phosphodiesterase 2A (PDE2A) inhibitors: a patent review (2010 - present). Expert Opin. Ther. Pat., 26, 933-946.

Vale, A.L., Green, S., Montgomery, A.M. \& Shafi, S. (1998) The nitric oxide synthesis inhibitor L-NAME produces anxiogenic-like effects in the rat elevated plus-maze test, but not in the social interaction test. J. Psychopharmacol., 12, 268-272.

Vanmierlo, T., Creemers, P., Akkerman, S., van Duinen, M., Sambeth, A. De Vry, J., Uz, T., Blokland, A. et al. (2016) The PDE4 inhibitor roflumilast improves memory in rodents at non-emetic doses. Behav. Brain Res. 303, 26-33.

Volke, V., Soosaar, A., Koks, S., Bourin, M., Mannisto, P.T. \& Vasar, E. (1997) 7-Nitroindazole, a nitric oxide synthase inhibitor, has anxiolyticlike properties in exploratory models of anxiety. Psychopharmacology, 131, 399-405

Volke, V., Wegener, G. \& Vasar, E. (2003) Augmentation of the NO-cGMP cascade induces anxiogenic-like effect in mice. J. Physiol. Pharmacol., 54, 653-660.

Wang, Z.Z., Zhang, Y., Zhang, H.T. \& Li, Y.F. (2015) Phosphodiesterase: an interface connecting cognitive deficits to neuropsychiatric and neurodegenerative diseases. Curr. Pharm. Des., 21, 303-316.

Xu, Y., Pan, J., Sun, J., Ding, L., Ruan, L., Reed, M., Yu, X., Klabnik, J. et al. (2015) Inhibition of phosphodiesterase 2 reverses impaired cognition and neuronal remodeling caused by chronic stress. Neurobiol. Aging, 36 , 955-970.

Yang, G., Kitagawa, K., Matsushita, K., Mabuchi, T., Yagita, Y., Yanagihara, T. \& Matsumoto, M. (1997) C57BL/6 strain is most susceptible to cerebral ischemia following bilateral common carotid occlusion among seven mouse strains: selective neuronal death in the murine transient forebrain ischemia. Brain Res., 752, 209-218.

Yoshioka, H., Niizuma, K., Katsu, M., Sakata, H., Okami, N. \& Chan, P.H. (2011) Consistent injury to medium spiny neurons and white matter in the mouse striatum after prolonged transient global cerebral ischemia. J. Neurotraum., 28, 649-660.

Zhang, C., Yu, Y., Ruan, L., Wang, C., Pan, J., Klabnik, J., Lueptow, L. Zhang, H.T. et al. (2015) The roles of phosphodiesterase 2 in the central nervous and peripheral systems. Curr. Pharm. Design, 21, 274-290.

Zhao, Y., Xiao, M., He, W. \& Cai, Z. (2015) Minocycline upregulates cyclic AMP response element binding protein and brain-derived neurotrophic factor in the hippocampus of cerebral ischemia rats and improves behavioral deficits. Neuropsychiatr. Dis. Treat., 11, 507-516.

Zhu, J., Mix, E. \& Winblad, B. (2001) The antidepressant and antiinflammatory effects of rolipram in the central nervous system. CNS Drug Rev., 7 , 387-398.

Zhuo, Y., Guo, H., Cheng, Y., Wang, C., Wang, C., Wu, J., Zou, Z., Gan, D. et al. (2016) Inhibition of phosphodiesterase-4 reverses the cognitive dysfunction and oxidative stress induced by Abeta25-35 in rats. Metab. Brain Dis., 31, 779-791. 